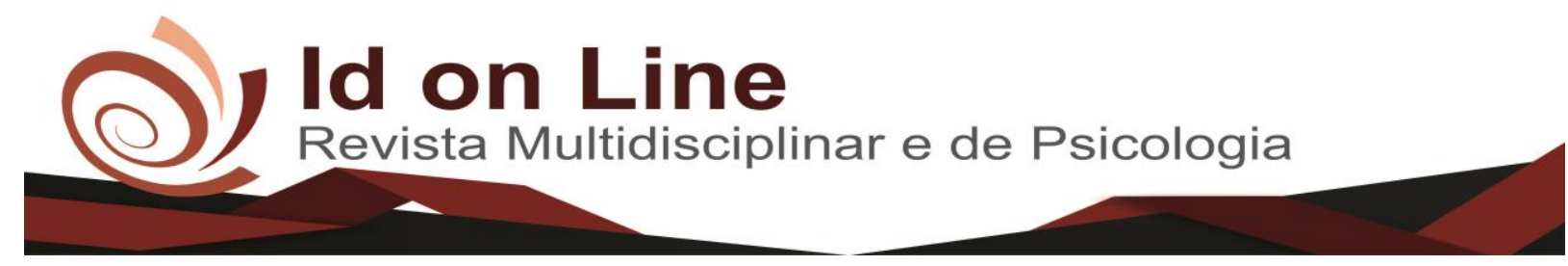

Estudo de Caso

\title{
Análise dos Serviços Logísticos de Distribuição de Bananas: Um Estudo de Caso na Empresa Sítio Barreiras
}

\author{
Maria das Graças Cavalcante Nunes ${ }^{1}$; Alyne Leite de Oliveira ${ }^{2}$; Hudson Josino Viana ${ }^{3}$; \\ Antonio Raniel Silva Lima ${ }^{4}$; Maria Patrícia de Alencar ${ }^{5}$
}

\begin{abstract}
Resumo: A logística agrega valor aos produtos desde sua origem até chegar ao consumidor final, buscando a satisfação destes e oferecer um produto com qualidade e diferencial para mercado, a presente pesquisa teve por finalidade analisar os serviços logísticos de distribuição da fruta banana, cujo processo requer especial manuseio e movimentação por apresentar um curto ciclo de vida. Através de um estudo de caso e observação assistemática dos fatos, foram analisados métodos e técnicas utilizados no campo em estudo, comparados ao embasamento teórico de autores que referenciam as práticas competentes aos processos logísticos no canal de distribuição. A pesquisa foi elaborada com objetivo descritivo, abordagem qualitativa, utilizado para coleta de dados a empresa Sítio Barreiras da cidade de Missão Velha, atuando desde 1996 com a fruta banana onde foi aplicada uma entrevista semiestruturada A construção da análise dos dados se deu através do método hipotético-dedutivo que levantado às hipóteses, segue uma linha de raciocínio afirmativo ou negativo dos fatos observados, apresentando um bom gerenciamento logístico em todo o canal de distribuição do produto, ajustando as necessidades e satisfação plena dos clientes, alinhando aos objetivos da empresa. Com amostragem não probabilística por cotas de conveniência aplicou-se um questionário aos principais clientes da cidade de Juazeiro do Norte, para levantamento de dados relacionados à satisfação dos mesmos, com elaboração de gráficos, os resultados obtidos mostraram o grau de eficiência das técnicas e procedimentos logísticos tornando o produto eficaz com agregação de valor, credibilidade e confiança entre empresa-cliente-consumidor.
\end{abstract}

Palavras Chave: Logística. Distribuição Física. Agregação de Valor.

\section{Analysis of Banana Distribution Logistics Services: A Case Study at the Sítio Barreiras Company}

\begin{abstract}
Logistics adds value to the products from its origin until reaching the final consumer, seeking their satisfaction and offers a product with quality and differential for the market, this research had the purpose of analyzing the logistics services of distribution of the banana fruit, whose process requires special handling and transportation because it has a short life cycle. Through a case study and asystematic observation of the facts, methods and techniques used in the field under study were analyzed, compared to the theoretical basis of authors who refer the competent practices to the logistic processes in the distribution channel. The research was elaborated with descriptive objective, qualitative approach, used for data collection the company Sítio Barreiras of the city of Missão Velha, acting since 1996 with the banana fruit where a semi-structured interview was applied The construction of the data analysis was done through the method Hypothetical-deductive hypothesis that follows the hypothesis, follows a line of affirmative or negative reasoning of the observed facts, presenting a good logistics management throughout the product distribution channel, adjusting the needs and full satisfaction of the clients, aligning with the company's objectives. With non-probabilistic sampling by quotas of convenience a questionnaire
\end{abstract}

${ }^{1}$ Graduada em Administração pelo Centro Universitário Doutor Leão Sampaio/UNILEÃO

${ }^{2}$ Especialista em Logística Empresarial, Orientadora da Graduação e Pós-Graduação da Faculdade Vale do Salgado/FVS e do Centro Universitário Doutor Leão Sampaio/UNILEÃO, membro do Comitê de Ética em Pesquisa alyneleite@leaosampaio.edu.br

${ }^{3}$ Especialista em controladoria e auditoria, professor de Marketing da Faculdade Vale do Salgado/FVS e coordenador do curso técnico em Administração da Escola Profissional Francisca de Albuquerque Moura/EPFAM-hudson.josino@gmail.com ${ }^{4}$ Professor da Graduação e Pós-Graduação da Faculdade Vale do Salgado/FVS e do Centro Universitário Doutor Leão Sampaio/UNILEÃO, Mestrando em Administração de Empresas (UNIFOR) - raniel@ leaosampaio.edu.br ${ }^{5}$ Graduada em Administração pelo Centro Universitário Doutor Leão Sampaio/UNILEÃO-patriciaalencar133@gmail.com

266 Id on Line Rev. Mult. Psic. V.12, N. 41, p. 266-293, 2018 - ISSN 1981-1179

266 Edição eletrônica em http://idonline.emnuvens.com.br/id 
was applied to the clients of the city of Juazeiro do Norte, to collect data related to their satisfaction, with elaboration of graphs, the results obtained showed the efficiency degree of logistic techniques and procedures, making the product effective with aggregation of value, credibility and trust between company-client-consumer.

Keywords: Logistics. Physical Distribution. Adding value.

\section{Introdução}

Logística é uma das atividades responsáveis pelo melhoramento do desempenho estratégico de produtos e serviços, interligados ao marketing, produção e financeiro que busca resultados positivos diante dos concorrentes, bem como o aumento da lucratividade e posicionamento da imagem da empresa no mercado (RAZZOLINI FILHO, 2006).

O mercado atual prioriza a satisfação plena do consumidor e clientes alinhando e ajustando os produtos ofertados à necessidade específica de cada segmento. A logística está inserida nas empresas independente de porte e segmento, promovendo melhorias na manutenção e movimentação de material sem distinção de gênero, vida útil e utilização de produto.

As empresas atuantes com produtos perecíveis priorizam a exclusiva movimentação e armazenamento que ocorre em um curto prazo de tempo, tendo em vista as mudanças, física, química ou biológica, o que pode prejudicar as suas qualidades para comercialização e consumo quando não armazenados e transportados corretamente nos locais de distribuição, venda e utilização.

Com o objetivo de analisar os serviços logísticos de distribuição do produto perecível banana na empresa Sítio Barreiras, a pesquisa apresenta como hipóteses, o bom gerenciamento logístico na distribuição do produto banana maximiza a qualidade da fruta agregando valor e o produto logístico é o resultado das aplicações das técnicas e o uso dos equipamentos corretos e transporte adequado para a movimentação dos materiais.

Diante de um mercado altamente competitivo as empresas buscam se destacar pela qualidade de seus serviços e/ou produtos, visando à conservação e aprimoramento das técnicas utilizadas no decorrer da circulação do produto, objetivando menos perdas e mantendo a qualidade, proporcionando relevantes vantagens competitivas. 
A pesquisa foi realizada diretamente no campo de aplicação das técnicas e procedimentos das atividades, onde o pesquisador se dispôs a observação dos processos e métodos utilizados dentro do canal de distribuição física da banana para coleta de dados e aplicação de uma entrevista com a pessoa responsável diretamente pelo o setor em estudo, bem como aplicação de questionário para mensuração do nível de satisfação dos clientes.

Esta pesquisa ampliou o conhecimento da prática da Logística no campo organizacional de forma que o pesquisador identificou a forma aplicável do conteúdo visto durante todo o curso de graduação em Administração de Empresas, conheceu a movimentação de produtos perecíveis para o caso estudado, cuja importância é o despertar para a competitividade imposta pelo mercado hoje, gerando a obrigatoriedade de melhoria na qualidade dos produtos e serviços oferecidos, focando o olhar para o processo produtivo, visualizando os benefícios com o aumento da qualidade do produto, aumento de lucros e minimização de perdas.

\section{Logística Empresarial / Evolução}

De acordo com Bowersox e Closs (2010) em meados da década de 50, as organizações praticavam as atividades logísticas de maneira inteiramente funcional, nada sabiam de integração. Ching (2009) diz que a logística por cerca de 1950, permaneceu em estado latente, as atividades eram divididas pela empresa em diferentes áreas que ocasionavam conflitos de objetivos e responsabilidades por não ter uma filosofia de comando.

$\mathrm{Na}$ antiguidade, a humanidade consumia os produtos em seus lugares de origens ou os conduzia para lugares distantes para armazená-lo e consumi-lo posteriormente. As mercadorias nem sempre estavam disponíveis em todas as épocas do ano, por não serem fabricadas próximas aos consumidores e sim, em regiões distantes (BALLOU, 2010).

Uma das causas que dificultou o avanço das atividades logísticas entre as décadas de 50 a 70 foi a evolução do conceito de marketing visto que as empresas estavam muito mais interessadas na compra e venda do que na distribuição física (BOWERSOX; CLOSS, 2010).

Para Ching (2009) o período correspondente às décadas 70 a 90 houve um avanço nos princípios básicos da logística, as empresas visavam mais os lucros do que o controle dos custos. Já na década de 90 foi marcada pelas grandes mudanças de infraestrutura para a 
disponibilidade de recursos operacionais computadorizados, obtenção de tecnologia da informação (BOWERSOX; CLOSS, 2010).

Bowersox e Closs (2010) destacam que um dos meios que propagou o desenvolvimento da logística foi a adoção do gerenciamento da qualidade total (TQM - Gestão da Qualidade Total), onde fazer as coisas da maneira correta logo na primeira vez foi adotado nas indústrias para obtenção de vantagens da qualidade em vista aos desafios lançados pela concorrência.

De acordo com Ching (2009) logística é definida como sendo a execução das tarefas relacionadas com o fluxo de materiais e de informações de forma contínua, desde o fornecedor ao consumidor final e vice-versa.

"Logística é o processo de planejamento, implantação e controle do fluxo eficiente e eficaz de mercadorias, serviços e informações relativas desde o ponto de origem até o ponto de consumo com o propósito de atender às exigências dos clientes" (COUNCIL OF LOGISTICS MANAGEMENT apud BALLOU, 2010, p. 27).

A Logística é composta por atividades de informações, transporte, estoque, armazenamento, manuseio de materiais e embalagem. Estas atividades alinhadas aos processos de movimentação e estocagem agregam valor ao produto, oferecendo qualidade no desempenho das tarefas e manuseio dos materiais em todo canal de distribuição interligada com as áreas de finanças, marketing e produção (BOWERSOX; CLOSS, 2010).

As organizações que monitoram seu desempenho logístico em busca da perfeição possibilitando possíveis falhas em tempo hábil, adotam providências antes da ocorrência, criam uma imagem de empresa preferencial e ideal por fornecedores e parceiros (CHING, 2009).

A logística hoje está voltada ao produto, cujo processo vai desde a matéria prima ao consumidor final e, é considerado um sistema que interligado as demais áreas que compõe a empresa visam melhoria dos seus processos, chamado de canal de distribuição (NOVAES, 2015).

\section{Atividades Logísticas Operacionais / Canal de Distribuição}

O canal de distribuição é o local onde ocorrem as atividades funcionais da logística, a esse conjunto de atividades dá-se o nome de cadeia de suprimentos, onde a matéria prima se 
transforma em produto acabado, agregando valor ao consumidor, uma vez que os pontos de matéria prima, produção, distribuição e venda não tem a mesma localização (BALLOU, 2010).

De acordo com Bowersox e Closs (2010) a cadeia de suprimento se dá por meio de série de ciclos de atividades que a logística de uma organização e o seu sistema operacional é vinculado, tanto interno como externamente, a clientes e fornecedores. $\mathrm{O}$ ciclo de atividades é mais facilmente compreensivo observando a estrutura e a dinâmica dos sistemas logísticos independente de tamanho.

Ballou (2010) diz que as atividades que compõem o sistema logístico variam de acordo com a estrutura da empresa, o conceito aplicado por cada gerente de acordo com a necessidade de atividades especificas e ramo de atividade executada. Podendo ser dividida em duas partes: atividades-primárias e atividades de apoio operacional.

As atividades primárias são compostas por padrão de serviço ao cliente, transporte, estoque, fluxo de informações e processamento de pedidos que operando interligadas dentro do canal de suprimento que trata das tomadas de decisões viabilizando suprir as necessidades específicas dos clientes, promovendo entrega de produto precisa e dentro do prazo (GONÇALVES, 2010).

Bowersox e Closs (2010) classificam três fatores importantes para o serviço ao cliente: disponibilidade, desempenho e confiabilidade, importante na predisposição do produto em estoque, a estrutura dos ciclos de atividades adequada a cada tipo de cliente atendido e a disposição de produtos e informações junto ao cliente gerando qualidade no desempenho operacional.

Segundo Bowersox e Closs (2010) as necessidades de estoque variam muito da disposição do nível de serviço ofertado ao cliente. O objetivo geral é fornecer o serviço desejado a este, mantendo o mínimo de estoque, estável e com menor custo total possível. A estratégia do gerente de estoque é conseguir máxima rotatividade cumprindo, ao mesmo tempo, os compromissos com os clientes.

O fluxo de informação e processamento de pedidos está ligado às informações junto ao cliente e despacho de pedidos com o emprego de tecnologia atual, podendo atender a demanda e requisitos em tempo real, bem como realizar soluções logísticas únicas e inovadoras (BOWERSOX; CLOSS 2010).

Deficiência na qualidade da informação pode gerar uma provável ruptura na cadeia de suprimento. Visto que maiorias das atividades logísticas ocorrem em antecipação a 
necessidades futuras, um erro na composição dessas necessidades ou um projeto, ou uma avaliação imprecisa pode resultar em falta ou excesso de estoque (BALLOU, 2010).

Gonçalves (2009) ressalta que o processamento de pedido acontece por meio de atividades que englobam o ciclo de pedido do cliente, que são: preparação, transmissão, recebimento e expedição do pedido e o relatório da situação do pedido. O tempo para processamento de um pedido depende do tipo do pedido. Uma venda do varejo é diferente de uma venda industrial.

Bowersox e Closs (2010) dizem que do ponto de vista do sistema logístico, existe três fatores fundamentais para o desempenho do transporte: custo, velocidade e consistência que visa os custos oriundos da movimentação, a escolha do modal conforme a velocidade e o custo de serviço e a confiabilidade de entrega e a manutenção dos materiais transportados.

O transporte por sua vez, segundo Ballou (2010) é um dos mais importantes segmentos da cadeia logística, é a entrega de mercadoria ao cliente, que são transportados por meios adequados, concluindo o ciclo operacional. Além da movimentação do produto, os transportes têm também por finalidade armazenar estes, quando estão no veículo. Empresas de grande porte possuem frotas de caminhões que locomovem as mercadorias e que garantem a exclusividade de entrega no destino, na localidade dos clientes unicamente da empresa. Outra opção são os serviços oriundos de transportadoras, empresas cuja atividade é prestação de serviço a várias empresas, fracionadas, com destinos variáveis que comprometem o prazo de entrega (BALLOU, 2010).

De acordo com Ching (2009) transporte é a atividade essencial e razão da logística que visa escolher o tipo de modal a ser usado, se único ou vários. Podendo ser classificados como rodoviário, ferroviário, aeroviário, aquaviário (marítimo e fluvial) e dutoviário.

O transporte rodoviário é o modal mais utilizado pela logística devido sua flexibilidade operacional com a atividade direta ao destino e a velocidade de movimentação intermunicipal que favorecem as atividades de produção e distribuição. As transportadoras rodoviárias são empresas que atuam como prestadoras de serviços eventuais realizada por caminhões, bem como frotas próprias das organizações tendo em vista retorno de investimento. Os demais modais são utilizados de acordo com o tipo do produto a ser transportado, seu destino e prazo de entrega. (BALLOU, 2010).

Sendo assim o objetivo da movimentação de materiais é a busca pela eficiência dessa atividade reduzindo custos à medida que aumenta o espaço utilizado. E esse aperfeiçoamento 
se dá através da prática desenvolvida ao longo de quatro linhas: a unificação da carga, o layout do espaço, a escolha do equipamento de estocagem e a escolha do equipamento de movimentação (BALLOU, 2010).

O uso de carregamentos padronizados tem por finalidade além da redução de custos a facilitação do manejo e transporte dos materiais. Estes permitem a redução dos custos de mão de obra, maiores agilidade na movimentação, melhor aplicabilidade dos equipamentos de movimentação e transporte e melhor aproveitamento do espaço cúbico (GONÇALVES, 2010).

A unificação da carga leva em consideração de que a economia está ligada diretamente ao tamanho da carga manuseada, pode-se dizer que quanto maior o número de materiais movimentados, menos viagens serão necessárias para atender as necessidades de estocagem. Reduz o tempo de circulação do produto e o tempo do uso dos equipamentos de manuseio de materiais exposto ao uso (BALLOU, 2010).

Para Ballou (2010) a eficiência pode ser melhorada no fechamento de carga como número de volumes menores numa única carga e consequentemente o manuseio da carga fechada. A esta operação dá-se o nome de unificação da carga feita por meio de paletização e conteinerização.

A paletização é uma estrutura de madeira ou material reforçado utilizada no carregamento de materiais facilitando o transporte e estocagem, é a uma base. Proporciona mais eficácia por ser manuseada por equipamentos mecânicos, facilita a unificação da carga devido o aumento do peso e redução do volume, aumenta a utilização do espaço por ser estocados empilhados, possibilitando estoques mais altos. A conteinerização é caixas grandes para estocagem e transportes de materiais. É melhor opção para unificação da carga. (BOWERSOX e CLOSS, 2010).

As atividades de apoio operacional são compostas por armazenagem, manuseio de materiais e embalagem. A armazenagem constitui a atividade que administra os locais a serem ocupados por materiais, podendo ser dentro da organização ou fora, que proporcionem qualidade na distribuição tanto de proximidade dos clientes quanto melhoria de disponibilidade dos produtos (POZO, 2004).

Segundo Bowersox e Closs (2010) são três as alternativas de armazenagem: depósitos próprios, públicos e contratados. Próprio quando a empresa é dona tanto do espaço como dos materiais manuseados. Público quando o serviço é prestado por terceiros, mediante pagamento 
de taxa fixa ou variável e depósito contratado é composto por um serviço ao longo prazo e compartilhamento dos riscos.

A segunda atividade operacional é o Manuseio de materiais é exercida dentro dos depósitos onde os materiais podem ser dispostos a granel ou em caixas. Segundo Ballou (2010) o manuseio de materiais está ligado diretamente ao tipo de decisão tomada quanto à estocagem desses materiais, na grande maioria é uma atividade que traz grandes custos, variando de acordo com o tempo do ciclo de pedido dos clientes e sobre o serviço ao cliente.

O Layout para separação dos pedidos requer um maior gasto de tempo do que na estocagem. Uma layoutização para a estocagem dos pedidos é necessário uma modificação referente à altura do empilhamento e localização dos produtos. O objetivo é diminuir o tempo de movimentação evitando longa distância no próprio armazém para atender aos pedidos, utilizando equipamentos especializados que reduz o tempo de movimentação na separação e fazendo uso de um projeto operacional de sequenciamento, zoneamento e formação de lotes (BALLOU, 2010).

A estocagem e o movimento de materiais são atividades que andam juntam, onde a estocagem é um tempo de parada dos materiais do armazém. A uma grande variedade de equipamentos de movimentação dos produtos no armazém, disponíveis tanto para carga e descarga e separação de pedidos (GONÇALVES, 2010).

Esses equipamentos se distinguem de acordo com a necessidade existente na estocagem para a movimentação dentro do armazém. São três as categorias abrangentes e bem caracterizadas de tais equipamentos: manual, misto (com o auxílio de energia) e totalmente mecanizado; podendo encontrar em um só armazém as três variações em uso (BALLOU, 2010).

São exemplos de equipamento manual os carrinhos de duas rodas e as paleteiras de quatros rodas, que viabilizam vantagens mecânicas no manuseio dos produtos e de baixo custo. Há uma variação de modelos adaptados para a movimentação de produtos especiais (tapetes, móveis, entre outros). Sendo limitado o seu uso a força física do operador. (BALLOU, 2010).

São exemplos de equipamento mistos os guindastes, truques industriais, elevadores e guinchos; O uso da empilhadeira, palete e prateleiras do armazém compõe um sistema que todo mundo conhece e utiliza por ter um custo baixo, sendo usados em uma área de armazenagem de cargas elevadas os equipamentos mecanizados requerem manuseios automáticos que são controlados por computadores, códigos de barra e tecnologia de escaneamento (BALLOU, 2010). 
A embalagem representa um grande impacto sobre os custos e a produção nos processos logísticos. Porém despercebido, os custos com embalagem são absorvidos por todo o canal de distribuição, a integração da logística e o planejamento centrado, com um controle dos custos totais proporciona relevante economias (GONÇALVES, 2010).

Segundo Bowersox, Closs e Cooper (2007) o emprego da embalagem em todas as operações logísticas gera um impacto sobre a produção e a qualidade nas atividades em todo o canal de suprimentos desde o carregamento de transportes e a operacionalização de separação de pedidos até sua movimentação e armazenagem em metros cúbicos no armazém.

Os ciclos de atividades logísticas trabalham continuamente de forma a atender às necessidades de entrada/saída. As tarefas realizadas com eficiência satisfazendo as exigências operacionais são pontos importantes no gerenciamento da logística e estão divididos em atividades de manufatura, suprimento e distribuição física (BOWERSOX; CLOSS, 2007).

Para Bowersox e Closs (2010) a manufatura está ligada à produção, cuja operação se dá entre a distribuição física e as operações de suprimento das organizações com grande importância para o controle e manutenção de um fluxo econômico de materiais e estoque. Já a atividade do suprimento compreende a logística de entrada, são semelhantes ao de processamento de pedido de clientes ao receber suprimentos.

As atividades de distribuição física influenciam os setores de marketing e das vendas que viabilizam a disponibilidade de produto com baixo custo em menor tempo possível, composto pelo processamento de pedidos de clientes e a entrega de mercadorias de forma pontual, precisos e completos ligando o cliente a empresa, onde busca atingir os objetivos do setor com desempenho zero de defeito com técnicas e estratégias certas a fim de reduzir os ativos e os custos (BOWERSOX; CLOSS, 2010).

\section{Operações Logísticas Integradas / Supply Chain}

Para Ching (2009) o novo conceito de logística integrada tem como objetivo impulsionar o fluxo contínuo de entrada de matéria prima (suprimento), transformação do produto (produção) e da saída de produto acabado até o ponto de venda (distribuição), sem 
interrupções durante o processo, de forma que diminua cada vez mais o uso dos estoques pela empresa (just-in-time).

Os ciclos das atividades logísticas de acordo com Bowersox e Closs (2010) são referência para análise da logística integrada por disponibilizar uma dinâmica básica das várias faces e das decisões que devem ser interligadas a um sistema operacional. O que inclui uma relação de fornecedores, empresa e clientes que ocorrem em todo o canal dos meios de comunicação e transporte.

Suppy chain é toda a ação planejada e controlada que envolve os processos e atividades organizacionais agregando valor ao produto e serviço para o cliente, criando uma relação cooperativa e benéfica desde os fornecedores até o consumidor final. A estrutura operacional das atividades logísticas integradas segundo Ching (2009) busca oferecer um controle de qualidade no desempenho, custo e flexibilidade, considerando a variedade dos mercados.

Alguns critérios devem ser analisados para que se possa obter uma redução dos custos de movimentação dos materiais e maximizar a acessibilidade, são estes: volume de armazenamento; peso do material; acondicionamento e embalagem; frequência de movimentação; rotatividade dos estoques; valor do material; critério de fornecimento e etc. (GONÇALVES, 2010).

\section{Logística de Distribuição}

Para obter uma distribuição eficaz se faz necessário a execução de várias funções distintas, fazendo com que o canal de distribuição desenvolva as atividades logísticas de forma a agregar valor de acordo com a forma, propriedade, tempo e local (BOWERSOX; CLOSS, 2010).

A finalidade maior da logística é agregar valor ao produto e serviços, sendo percebida diferentemente pelos clientes, essa agregação ocorre de diversas formas, considerando a diferença entre o que o cliente está disposto a pagar pelos produtos e serviços menos receitas pagas ao fornecedor (CHING, 2009).

Sendo a atividade que trata das relações empresa-cliente-consumidor, Ching (2009) ressalta que as empresas direcionam seu olhar para a cadeia de abastecimento e o papel que ela desenvolve, criando fatores de mudanças dispondo novas tecnologias e inovações nas 
modalidades de serviços de transporte oferecendo perspectivas relevantes para o redesenho dos fluxos de produtos.

A correlação entre distribuição e trade marketing que significa melhoria ou evolução da relação entre o Fabricante e o Distribuidor, segundo Arbache (2011) está ligada a integração das funções chaves que juntas dão suporte ao processo de venda, cujos aspectos principais são: distribuição para o ponto de venda e distribuição no ponto de venda, desde que satisfaçam as necessidades dos clientes e consumidores.

As demandas de clientes moldam os padrões de distribuição que segundo Ching (2009) são: Serviço ao cliente que cada vez mais se exige maiores níveis de atividade, executando entregas no tempo certo, sem erros e estoques disponíveis. Os custos, trabalhados de forma a alinhar redução de gastos com manutenção das margens de lucros e considerando a força da competitividade e a velocidade que muito contribui para a redução dos ativos e dos custos.

De acordo com Santana (2006) as características do produto oferecido pelas empresas aos clientes diferem em preço, qualidade e serviço que alcance níveis fundamentado na combinação dessas características, adquirindo e fidelizando clientes de classes diferentes ou até mesmo novo segmentos de mercado.

A gestão eficaz nos canais de distribuição eleva o nível de avaliação dos serviços, contribuindo com a formação de clientes e posicionamento da marca da empresa no setor diante dos concorrentes. Não há valor para o produto sem que este chegue às mãos do consumidor, sem que haja uma demanda a ser satisfeita (ARBACHE, 2011et al).

O papel principal do canal de distribuição segundo Ching (2009) é manter o nível crescente de serviço, garantindo produtos com qualidade, sempre buscando minimizar as devoluções por avarias decorrente do manuseio no processo de distribuição e disponibilizar com rapidez as demandas. É responsável pela administração de materiais desde a saída do produto da linha de produção até chegar ao consumidor final, atendendo os seus pedidos ou demanda contínua que segundo Arbache et al (2011) é composta por macroprocessos que são: Logística de entrada ou inbound logistics, logística interna ou de operações e logística reversa, dispostas a seguir. 


\section{Logística de entrada ou inbound logistics}

Logística que trata da relação empresa-fornecedores é a atividade ligada à produção, cuja operação se dá entre a distribuição física e as operações de suprimento das organizações com grande importância para o controle e manutenção de um fluxo econômico de materiais e estoque a fim de cumprir cuidadosamente as necessidades oriundas dos processos produtivos (BOWERSOX; CLOSS, 2010).

\section{Logística interna ou de operações}

Responsável pelo o controle das movimentações e dos estoques na linha de produtiva são atividades semelhantes ao de processamento de pedido de clientes, devidos os aspectos de execução ser iguais. Ao receber suprimentos, há necessidade de armazenagem, manuseio e transporte, considerando o tempo de entrega, tamanho das cargas, método de transporte e o valor dos produtos que se diferenciam no suprimento, sempre voltado para a minimização dos custos (BOWERSOX; CLOSS, 2010).

De acordo com Ching (2009) esse é o ciclo responsável pela distribuição física do produto acabado até o ponto de venda ao consumidor assegurando o despacho dos pedidos pontualmente entregues, precisos e completos. Composta por serviço ao cliente, custo e velocidade com serviços integrados a toda a cadeia logística como forma de obter as técnicas e estratégicas certas a fim de reduzir os ativos e os custos.

\section{Logística reversa}

Segundo Arbache (2011) logística reversa compreende ao movimento inverso do produto, oriundas do cliente para a empresa, é o canal de distribuição reverso, processo que cresceu com a conscientização de reciclagem criada pela sustentabilidade e responsabilidade social. 
Tendo início nos pontos de consumo dos produtos e fim nos pontos de origem, seu objetivo é reter valores num processo de reciclagem economicamente importante. Este processo envolve intermediários, pontos de armazenagem, transportes, finanças, etc. (Novaes, 2004).

Segundo Leite (2003 apud NOVAES, 2004) o canal de distribuição reverso se divide em dois: canal reverso de pós-consumo, produtos com vida útil que após uso, necessita ser destruídos é o caso dos produtos eletrônicos e o canal pós-venda, relacionado ao retorno de embalagem e a devolução de produtos ao varejista ou fabricante, de forma a alcançar a plena satisfação do consumidor. A reciclagem é o processo em que o produto passa por transformações que possibilita a produção de novos produtos, completando seu ciclo de vida.

\section{Ciclo de Vida do Produto}

O produto segundo Las Casas (2009) é inserido no mercado e até a sua retirada passa por diversas fases: introdução, crescimento, maturidade e entram em declínio entre várias razões a falta de atualização do produto ou estratégia de marketing levam o declínio dos demais. Para a logística de acordo com Ballou (2010) a distribuição física ocorre de forma diferenciada no decorrer do ciclo de vida dos produtos por ser indefinido o padrão de volume de vendas que requer uma estratégia cautelosa com estoques.

Com o avanço tecnológico nos dias atuais, os produtos sofrem diversas transformações em um curto espaço de tempo. O produto da cadeia de suprimento/logístico é o complexo de características que o profissional de logística tem a sua disposição para ajustar aos objetivos da empresa. Modificando ou readaptando o produto obtêm consequentemente mudanças de posicionamento no mercado e uma real vantagem competitiva (CHING, 2009).

Os aspectos peso, volume, valor, perecibilidade, inflamabilidade e substituibilidade próprio do produto influência sobre a estratégia logística como indicadores do emprego adequado de armazenagem, estocagem, transporte, manuseio de material e processamento de pedidos, fazendo menção a quatro categorias de atributos para melhor entendimento: quociente peso-volume, quociente valor-peso, substituibilidade e características de risco (BALLOU, 2010).

Ching (2009) aborda que as exigências do mercado criam dentro da empresa grande impacto. Estratégias são criadas a fim de acompanhar o desenvolvimento e ter um melhor nível 
de desempenho diante dos concorrentes, esta pratica requer investimentos em equipamentos, sistemas e qualificação visando atualizar seus processos, redesenhando ou criando novos produtos, objetivando o aumento da competitividade e aquisição de uma maior fatia do mercado.

\section{Metodologia}

Pesquisa de acordo com Gil (2010) é uma forma de investigação fazendo uso da razão e sistematicamente se propõe responder dúvidas a fatos que não se tem total conhecimento. $\mathrm{O}$ método utilizado foi o hipotético dedutivo que segundo Oliveira (2010) é a forma que conduz a investigação em busca de conhecimentos e levantamentos de hipóteses dos problemas em questão que serão testados para uma definição das conclusões, quanto à natureza é uma pesquisa aplicada que para Kaucak, Manhãis e Medeiros (2010) tem por objetivo adquirir conhecimento para aplicação prática de respostas aos problemas específicos dentro de uma realidade e interesses locais.

A pesquisa é descritiva que segundo Gil (2010) relaciona as características de determinado fato com a finalidade de identificar possíveis afinidades entre variáveis que conduz a uma análise aprofundada da realidade pesquisada. Quanto à abordagem é uma pesquisa qualitativa que de acordo com Oliveira (2010) trata-se de uma observação minuciosa e racional dos fatos a fim de examinar com exatidão, utilizando procedimentos adequados para entendimento do objeto em estudo. Com fontes bibliográficas o mesmo autor relata que esta é uma forma de averiguar documentos, livros, periódicos, enciclopédias e artigos científicos para um estudo maior sobre o tema.

Sendo um estudo de caso foram analisados os dados, os procedimentos conforme Ludwig (2010) trata de uma observação das atividades especificas no campo de aplicação que abrange a história do objeto em estudo, através de uma narrativa do seu contexto original e da situação atual. A coleta de dados foi realizada na empresa Sítio Barreiras Fruticultura Ltda., situada na zona rural da cidade de Missão Velha, produtora e distribuidora de frutas, mais especificamente de banana, cujo objeto de estudo foi o canal de distribuição logístico.

A amostra de dados envolveu o gestor da empresa mencionada atuante no setor logístico onde aplicou uma entrevista aberta semiestruturada que segundo Oliveira (2010) visa à busca 
de dados discriminados sobre o fato pesquisado com questões e segmentos específicos, mas com plena liberdade de respostas. Com amostragem não probabilística por cotas de conveniência, foi aplicado um questionário aos principais clientes da cidade de Juazeiro do Norte, com seis questões fechadas de múltipla escolha que segundo Mattar (1996) dentre as vantagens, elas são de rápido preenchimento, fácil tabulação e análise dos dados, com várias opções de respostas tem como vantagem a coleta de dados mais aprofundados.

Como instrumentos complementares para a coleta de dados utilizou-se papel, caneta e gravador de voz para que os dados fossem registrados e analisados segundo a fala da pessoa que foi entrevistada e a fim de que nenhum dado importante se perca.

Os dados foram analisados de forma descritiva com a transcrição de aspectos relevantes mencionados na entrevista, bem como realizando a correlação da observação realizada. $\mathrm{O}$ pesquisador fez uso da metodologia Hipotético-Dedutiva que segundo Marconi e Lakatos (2011), são uma abordagem que apresenta em primeiro lugar o surgimento de um problema e as hipóteses, que foram analisados pela observação e experimentação.

A presente pesquisa foi submetida à avaliação do Comitê de Ética em Pesquisa de acordo a resolução 510/16 do Conselho Nacional da Saúde (CNS), que regulamenta as diretrizes e normas de pesquisas envolvendo seres humanos, por apresentar riscos para os entrevistados como disponibilidade de tempo, compartilhamento de informações pessoais ou confidências ou em alguns tópicos que ele possa se sentir incômodo em falar. Estes riscos foram minimizados pelo pesquisador que marcou antecipadamente dia e hora de acordo com a disponibilidade de cada um e elaborou previamente os temas e questões chaves da entrevista que ocorreu como discursões, dando tempo ao entrevistado para manifestar sua opinião a sua própria maneira, podendo fazer correções e adicionar informações.

Quanto ao participante desta pesquisa não teve nenhum benefício direto, o esperado que este estudo venha fornecer informações importantes sobre a logística de distribuição da fruta banana, de forma que o conhecimento que será adquirido a partir desta pesquisa possa servir de referência para futuras pesquisas dentro do tema abordado, onde o pesquisador se compromete a divulgar os resultados obtidos. 


\section{Análise e Discussão dos Resultados}

Visando-se atingir os objetivos da pesquisa, a análise e discussão dos dados estão apresentadas em tópicos de acordo com cada atividade chave que compõe o canal de distribuição: Logística de entrada, Logística interna ou operacional e Logística reversa, interligando aos objetivos propostos pela pesquisa.

Os resultados do estudo estão apresentados de acordo com as observações realizadas no campo da pesquisa e com as perguntas oriundas da entrevista com o gestor da empresa Sítio Barreiras situada na cidade de Missão Velha, assim como as discussões viáveis dos conceitos desenvolvidos na revisão da literatura e mensuração do nível de satisfação dos principais clientes.

Inicialmente foi caracterizada a abrangência do objeto de estudo, as atividades decorrentes no campo, etapas dos processos, metas a serem alcançadas e satisfação do cliente. Os dados coletados revelam informações fundamentais para compreensão dos procedimentos e técnicas utilizadas para o melhoramento e manutenção do produto perecível banana.

\section{Logística de Entrada ou Inbound Logistics}

A logística inbound de acordo com a observação realizada no campo de estudo, o suprimento da cadeia se dá de acordo com a demanda de pedidos dos clientes que chegam à gestão da fruta, através de um sistema integrado ao comercial. É quantificado o total de bananas a serem despachadas segundo o cálculo para 2.000 caixas: 2000/1.3 (coeficiente de quantidade de bananas em um cacho) é igual à quantidade de cachos necessários para a demanda (1538 cachos), dado esse mencionado na entrevista com a gestora responsável.

Sendo a colheita própria dentro do Sítio, é utilizado um reboque como meio de transporte da fruta do cultivo ao galpão de produção. Faz-se o cálculo para saber quantos reboques serão necessários para a realização deste processo, dividindo a quantidade de cachos 1538 por 28 (quantidades de cachos suportados pelo reboque), resultando em 54 reboques de bananas. 
Tendo em vista que a logística agrega valor de qualidade, conforme mencionado por Bowersox e Closs (2010) o reboque é preparado de forma adequada a receber os cachos de bananas, isto é, são colocados colchonetes e a própria folha da banana para proteção, evitando danos à fruta como arranhões, e todos os cachos chegam envolvidos por um plástico que durante o seu crescimento o protegeu dos insetos.

Os cachos são dispostos em todo o galpão em cabos aéreos (trilhos pendurados por carretilhas) em fileiras onde é feito a desflora, processo de retirada de restos florais localizados na ponta da fruta, retira-se também àquelas que apresentam danos como amassadas, lesão, manchas, danos profundos, queimados pelo sol, podridão e imaturo, para em seguida despencar os cachos fazendo uso da estrovenga de despencar (ferramenta apropriada para despencar os cachos de banana). Este processo é feito próximo ao tanque com água onde são colocadas as pencas evitando desperdício de tempo, esse fato contribui para a eficácia do mesmo, pois conforme cita Novaes (2015) a logística está voltada ao aprimoramento do produto, cujo processo vai desde a matéria prima até o consumidor final.

A gestora da empresa destaca na entrevista que são cultivadas a banana nanica e a prata, apresentando uma maior clientela para a prata devido à cultura do local. Esse tipo de fruto por sua vez, requer um baixo investimento, sua casca é mais sensível aos procedimentos, já a nanica por ter uma casca mais grossa e demorar no processo de amadurecimento, requer técnicas apropriadas, tem um círculo de vida maior.

O padrão da fruta é classificado como sendo de $1^{\text {a }}$ (primeira) - comum e super: nanica 30 a 37 de diâmetro e comprimento que vai de 17,5 a $22 \mathrm{~cm}$ e a prata - 30 a 40 diâmetro e comprimento 16 a $22 \mathrm{~cm}$, cujo controle de qualidade é realizado a cada 1000 caixas, onde se avalia cinco (05) ou de quatro em quatro horas de processos, fazendo uso do calibrador de frutas e régua com o intuito de perceber a qualidade da colheita, danos causados e identificar problemas para a devida correção. Por caixa são observados: tamanho, calibre (grossura), quantidade total, quantidade por dedos, buquê e penca (sabendo que penca contém mais de nove (9) frutos, buquê de dois (2) a nove (9) frutos e dedos um (1) fruto).

A gestora diz ainda que o restante é banana de $2^{\mathrm{a}}$ (segunda) que apresentam danos e defeitos leves superficiais que não inviabilizam o consumo e/ou a comercialização, mas prejudicam a aparência e a qualidade do produto, tais como: tamanho, espessura, desenvolvimento diferenciado, lesões e manchas. 


\section{Logística Interna ou Operacional}

Segundo Arbache (2011) a logística da planta é responsável pelo controle da movimentação e estocagem dos materiais em toda a cadeia de suprimento. O desenvolvimento das atividades ocorre de forma contínua para a transformação do produto, as pencas são colocadas em tanque de alvenaria que contém água, cloro e detergente disposto no centro do galpão com o objetivo de retirar a nódoa e limpar a fruta. A água é movida por motores que ajudam na movimentação da fruta em todo o tanque, também é utilizada uma travessa (ferramenta manual de movimentação da banana no tanque) que facilita o trabalho dos operários em juntar as pencas dispersas.

O tanque funciona como uma linha de montagem onde o produto é transformado de pencas para buquê contendo de 5 a 8 bananas, classificando-os em: $1^{\text {a }}$ - comum ou super, banana padronizada e de $2^{\mathrm{a}}$ - qualidade inferior para em seguida serem expostas na esteira rolante que auxilia na selagem.

Embalados em caixas plásticas, são pesados e colocados em pallets de madeira, com arranjo de cinco (5) caixas e empilhamento com (9) de altura, resultando em um pallets de 45 caixas. Para minimizar tempo e esforço os operários fazem uso do abaixador de pallets (guindaste para armazém conduzido pelo sistema elétrico, instalados no rés-do-chão). Em seguida são lacrados com fitas e etiquetados. As embalagens plásticas, ao retornar dos clientes, são higienizadas e separadas por cores e tamanho com o objetivo de identificar o tipo da banana e o cliente e cada caixa pesa de $16 \mathrm{~kg}$ a $35 \mathrm{~kg}$ dependendo do seu tamanho.

Segundo a gestora através do software é gerado a ordem de produção, que especifica o pedido do cliente, quantidade de caixas a serem despachadas e o tipo de banana, são emitidas etiquetas para identificação contendo nome da empresa, código do cliente, tipo banana, peso, data provável da chegada, código de barra e a cor da etiqueta identifica o tipo de banana. Estas etiquetas são colocadas nas caixas dos pallets formados anteriormente.

Os pallets são transportados para o armazenamento em câmaras frias através da paleteira, equipamento manual que auxiliam na movimentação de materiais.

Na câmara fria os pallets são organizados por cliente e tipo de banana, enfileirados de forma que possibilite a circulação de ar em todos os empilhamentos, tem duas funções, resfriar e climatizar. É resfriada à 16C. O controle do armazenamento se dá por ficha de controle que contêm data, tipo de bananas, estoque com gás, sem gás, destino e quantidade. Esse fluxo de 
informação e processamento de pedidos segundo Bowersox e Closs (2010) está ligado às informações juntos ao cliente e despacho de pedidos com o emprego de tecnologia atual, podendo atender a demanda e requisitos em tempo real, bem como realizar soluções logísticas únicas e inovadoras (BOWERSOX; CLOSS 2010).

No seu relato a gestora diz que resfriar é manter sobre um clima mais frio a fim de conservar a qualidade da fruta e preparar para a climatização. A climatização é o processo que viabiliza o amadurecimento da fruta de forma homogênea. A câmera é composta por ventiladores que circulam o ar por igual e umidificador, utilizado para colocação do gás Etileno - um processo equivale à absorção do gás por um período de quatro (4) horas. A principal função do gás etileno está no amadurecimento dos frutos de uma maneira acelerada.

A mesma relata ainda que a climatização ocorre de acordo com tipo de banana, com os pedidos dos clientes e prazo de entrega. Quanto ao tipo, à banana prata por ser uma fruta com casca fina e sensível passa apenas por um procedimento, já a nanica possui uma casca mais grossa, demorando a absorção do gás, sendo necessário passar por três processos.

Figura 1: Tabela Climatização

\section{Fases da Banana de acordo com o amadurecimento}

01 Verde

02 Verde Claro

$\mathbf{0 3}$ Verde

04 Mais amarelado

05 Amarelada com pontas verdes

06 Totalmente amarela

07 Amarelas com
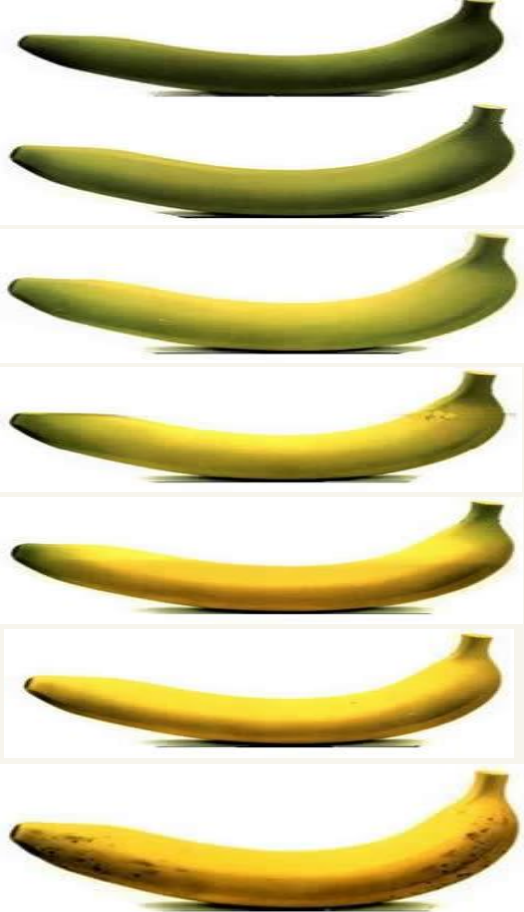

Completamente madura, com melhor sabor e maior valor nutritivo.

Fonte: <<http://baltazarbananas.com.br/site/index. php/curiosidades-da-banana/fases-da-banana >> (adaptado Baltazar Bananas Climatizadas - 2016) 
Entre cada processo faz-se exaustão para retirada do ar e entrada de um novo na câmara. Iniciada a sessão, a câmara não poderá ser aberta para que não ocorra perda da eficiência do gás, podendo prejudicar a qualidade da fruta.

Este processo pode ser realizado na movimentação do produto até ao cliente no intuito de apressar e cumprir o prazo determinado de entrega, como também em viagens de longas distâncias onde o objetivo é entregar a fruta no ponto de classificação solicitada pelo cliente. Segundo a gestora, o armazenamento do produto e os processos de climatização variam de acordo com a ordem de pedido do cliente. O cliente tem a opção de recebimento da fruta seguindo a classificação da banana que vai desde o ponto $\mathrm{C} 1$ ao $\mathrm{C} 7$. O ponto de comercialização é o C3, por está na cor ideal para conservação em estoque e manutenção em gôndolas devido ao clima da região.

Os três primeiros pontos são mais trabalhados dentro canal de distribuição. Utilizar a classificação da banana é unificar a linguagem do mercado e de toda cadeia de produção, dados estes apresentados na figura acima. Ao se observar todo o processo descrito percebe-se, que há preocupação com normas e procedimentos que vão culminar com a satisfação do consumidor, porém não se pode negligenciar a distribuição física, pois de acordo com Ballou (2010) as empresas de grande porte possuem frotas de caminhões que locomovem as mercadorias e que garantem a exclusividade de entrega no destino, na localidade dos clientes unicamente da empresa. A empresa possui frota própria e oficina mecânica preparada para a manutenção dos seus carros que são revisados e higienizados antes das viagens. A fruta requer transporte adequado para conservação da qualidade e realização dos processos necessários durante sua movimentação, são resfriados a 11C.

A gestora afirma que depois do visto o caminhão é conduzido até a plataforma para o carregamento. Através da comanda de carregamento os pallets são organizados no caminhão de acordo com o destino de cada pedido. Ao climatizar a fruta no caminhão é expelido na carga 17 minutos de gás e lacrada, vindo abrir somente no cliente, ressalvo a distancia e o tamanho da carga que varia este processo. O motorista é treinado para executar os procedimentos finais, controlar a temperatura ou fazer exaustão em viagens longas entre os processos. A mercadoria é entregue de acordo com as notas fiscais ou comanda e sujeitas à conferência. A empresa trabalha com promotores nas lojas que realizam o serviço pós venda como exposição do produto na loja, estocagem e futuros pedidos não deixando que ocorra quebra de fornecimento do produto e muito menos excesso. 


\section{Logística Reversa}

A logística reversa é responsável pela movimentação contrária dos produtos oriundos dos clientes para a empresa. Na empresa Sítio Barreiras essa logística é responsável pelo retorno dos materiais de uso para embalagem e transporte seguro da carga, bem como os comprovantes de recebimento dos produtos assinados pelo cliente. O cliente remete as caixas, os fitilhos e os pallets de madeira que serviram de suporte para o transporte de voltam para o caminhão, algumas empilhadas e outras por serem caixas versáteis são desmontadas e acopladas uma na outra para economia de espaço e organização. Também podem ocorrer devoluções decorrentes de erros na qualidade do produto entregue como, não amadurecimento ou manchas. Ao retornar para a empresa, as caixas são conferidas, contadas e lavadas, ficando assim preparadas para a próxima remessa.

Segundo Arbache (2011) este processo cresceu com a conscientização de reciclagem criada pela sustentabilidade e responsabilidade social, um dos pontos fortes da empresa mencionada.

\section{Níveis de Satisfação do Cliente}

Considerando todo o processo, uso de equipamentos e comprometimento organizacional para com a agregação de valor preconizado pela logística, ressalta a percepção dos consumidores atendidos pela empresa em estudo. Foram selecionados para tanto, uma amostra por julgamento, os principais clientes por ela atendidos.

Levou-se em conta ser da cidade de Juazeiro do Norte, por acessibilidade do pesquisador e ter realizado compras no último ano, constituindo uma amostragem não probabilista por cotas de conveniência. 
Gráfico 1: Fidelização de clientes

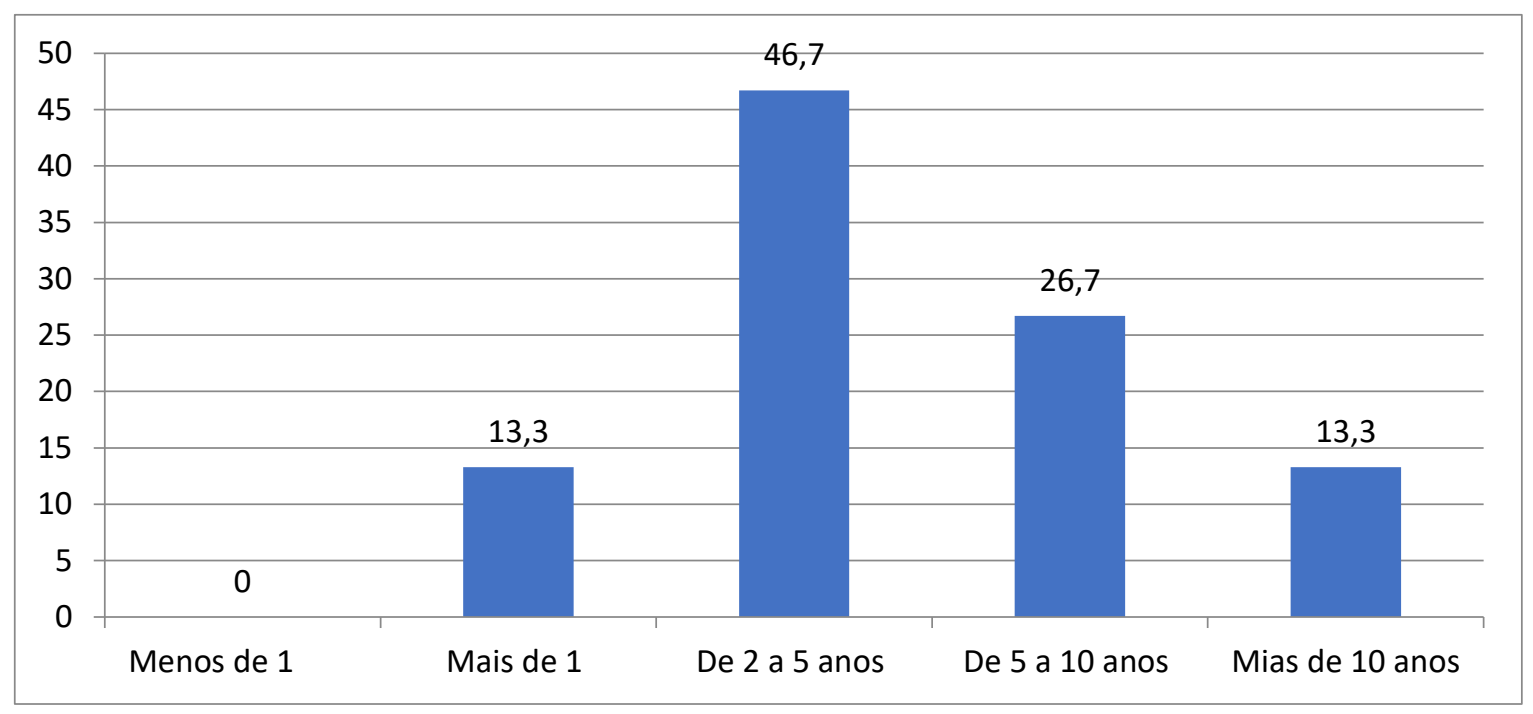

Fonte: Dados da pesquisa (2016).

Tanto no gráfico 1 com no gráfico 2, demonstra uma continuidade no relacionamento. As compras acontecessem na maioria semanalmente e diariamente, com uma soma de 73,3\% e 6,7\% eventualmente, o poder de compra dos clientes é notado neste gráfico como um alto giro de mercadorias, garantindo assim um fluxo contínuo do capital de giro.

Gráfico 2: Frequência de compras

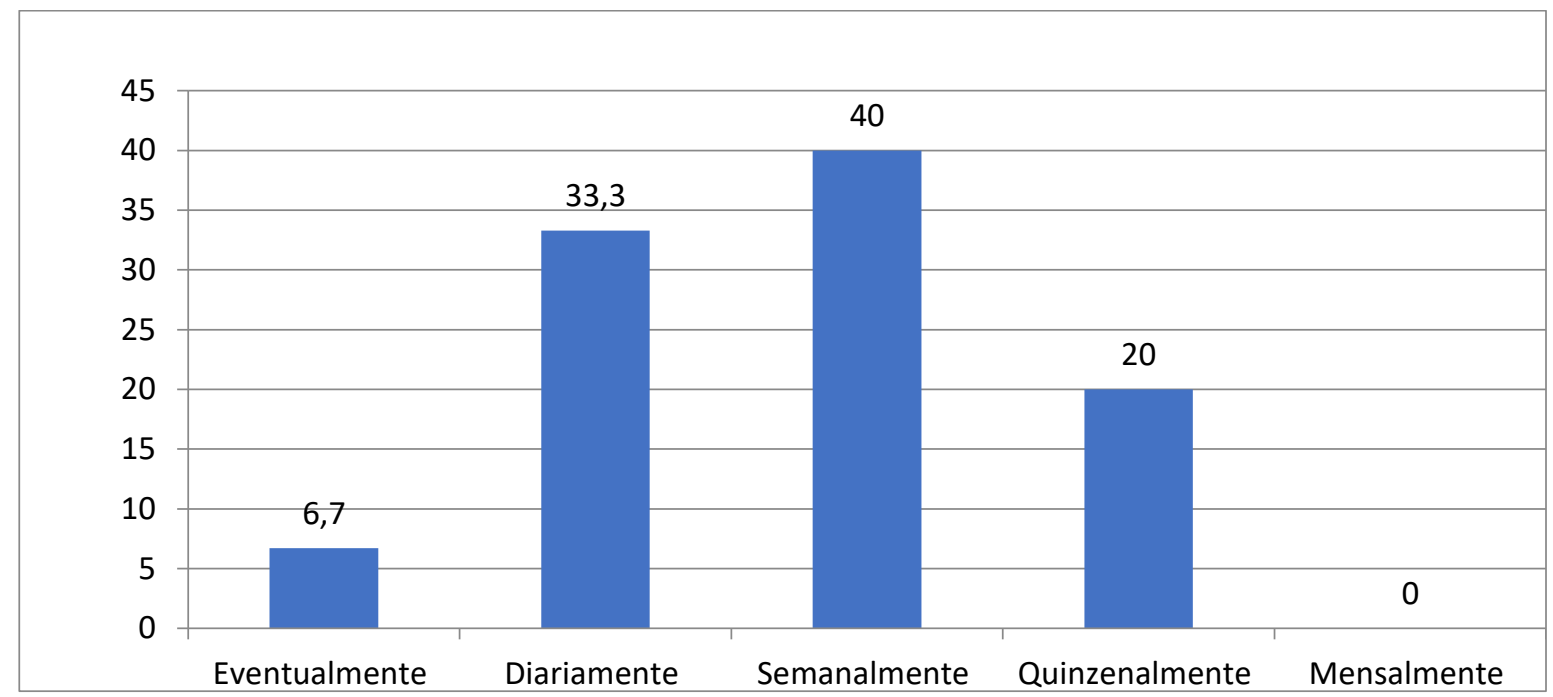

Fonte: Dados da pesquisa (2016). 
No gráfico abaixo os clientes avaliam a qualidade do produto com nota (4), onde cinco (5) é a nota ótima. Ressaltando que não houve notas inferiores, se somado as notas quatro (4) e cinco (5) obtidas do resultado, percebe que $100 \%$ dos clientes deram notas boas e ótimas, demonstrando um bom nível de satisfação com o produto recebido.

Gráfico 3: Análise da qualidade da fruta e dos serviços logísticos

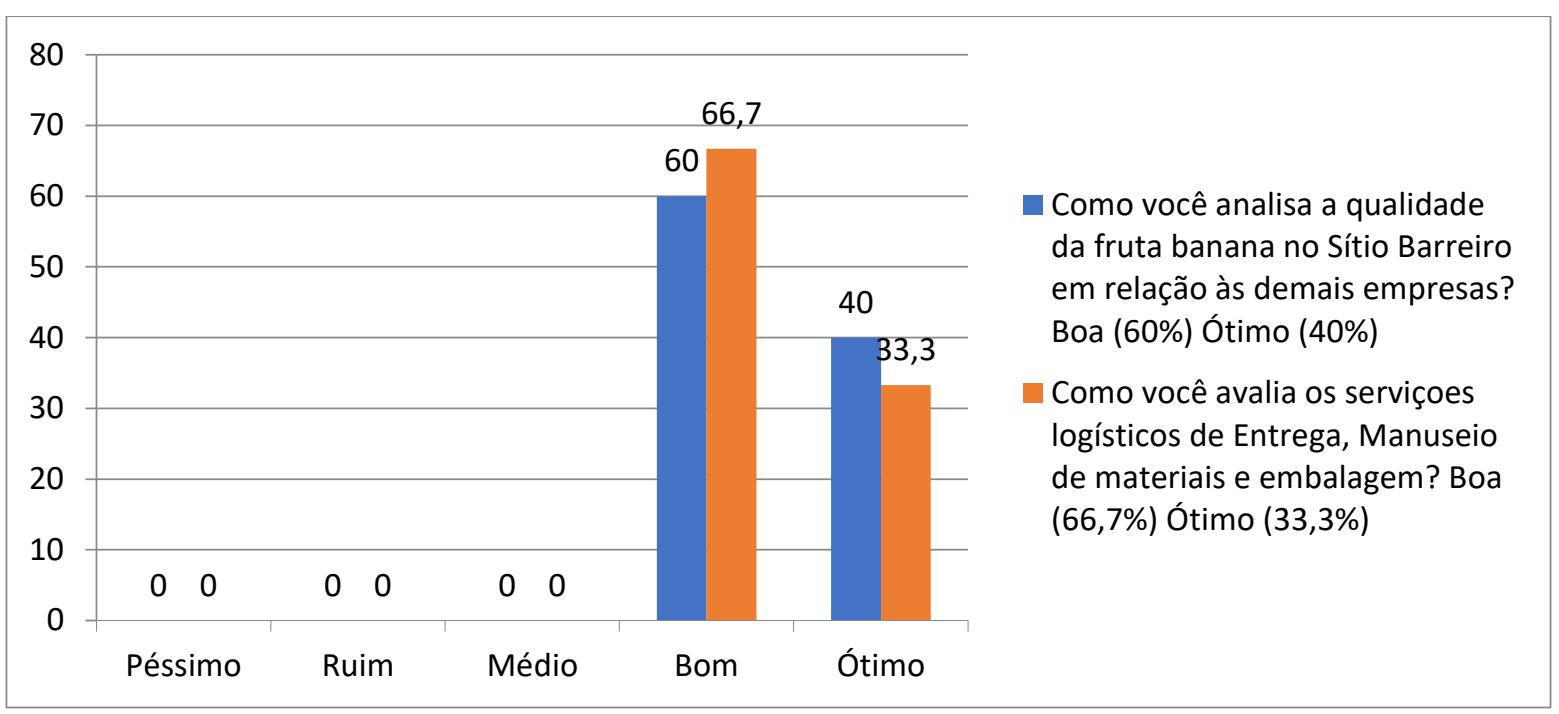

Fonte: Dados da pesquisa (2016).

Da mesma forma ocorreu com a nota que avalia os serviços logísticos e prazo determinado para entrega, dentro dos processos logísticos Bowersox e Closs (2010) classificam três fatores importantes para o serviço ao cliente: disponibilidade, desempenho e confiabilidade, importante na predisposição do produto em estoque, a estrutura dos ciclos de atividades adequada a cada tipo de cliente atendido e a disposição de produtos e informações junto ao cliente gerando qualidade no desempenho operacional. 
Gráfico 4: Entrega dos pedidos dentro do prazo determinado

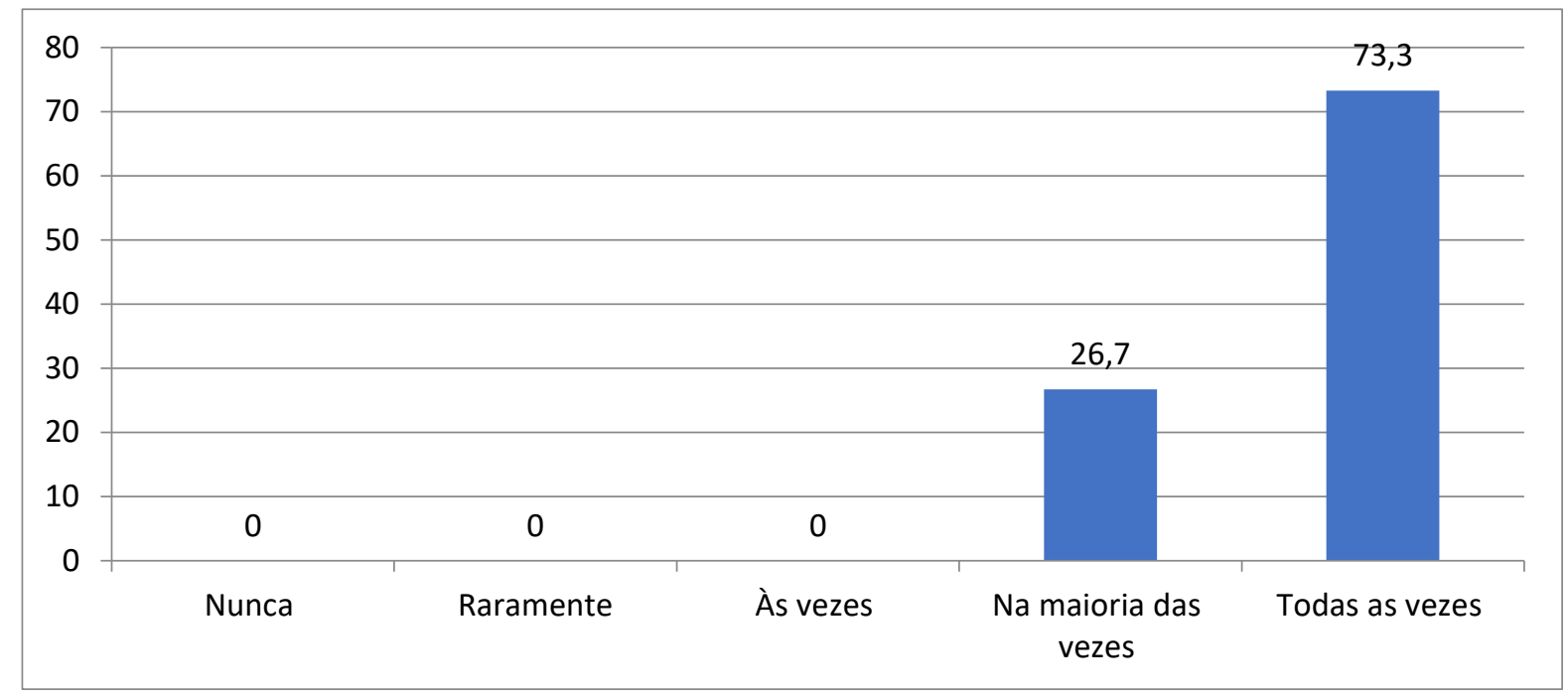

Fonte: Dados da pesquisa (2016).

As organizações que monitoram seu desempenho logístico em busca da perfeição intervêm as falhas em tempo hábil, adotando providências antes da ocorrência, criam uma imagem de empresa preferencial e ideal por fornecedores e parceiros (CHING, 2009).

Gráfico 5: Nota de satisfação do cliente

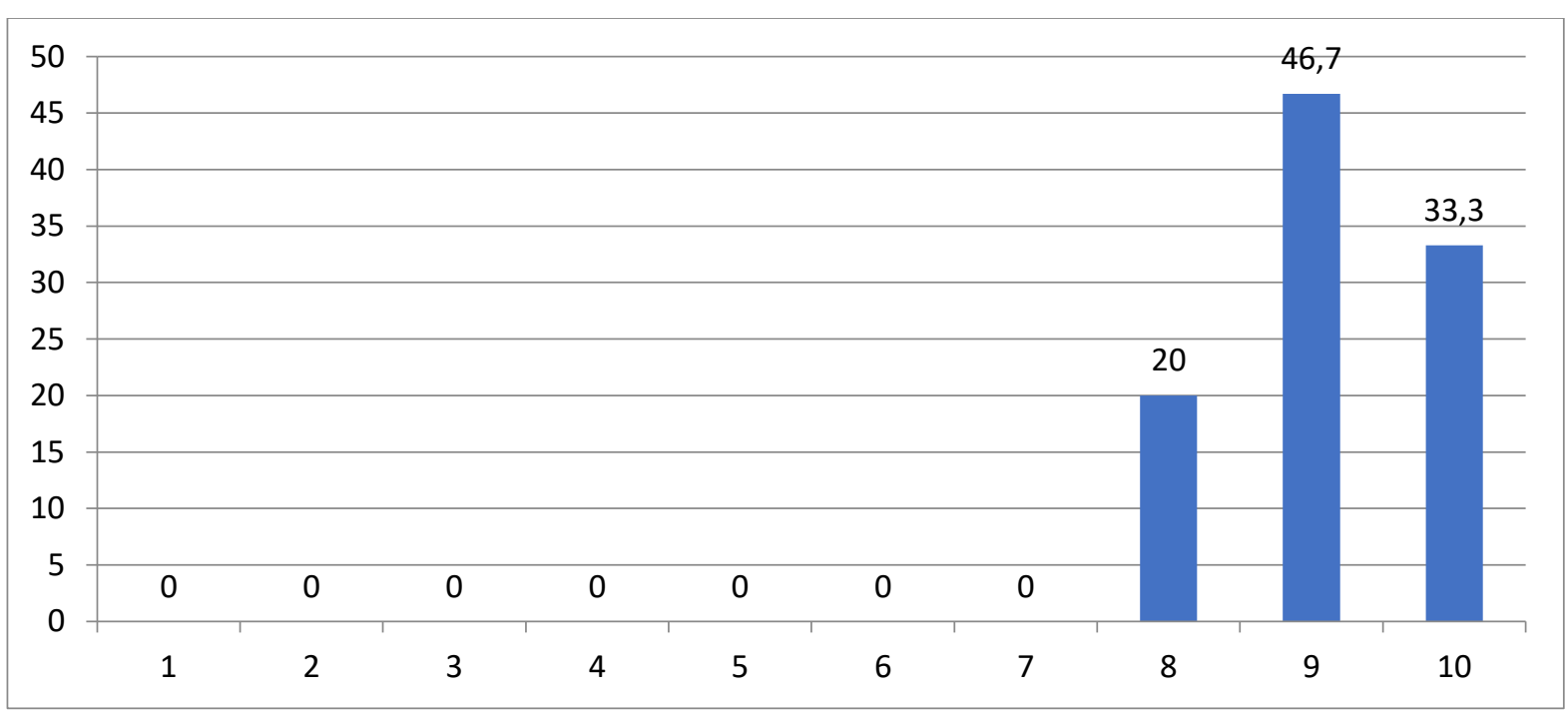

Fonte: Dados da pesquisa (2016). 
A análise de eficiência nos resultados obtidos através das notas de avaliações dos clientes evidencia o bom gerenciamento, resultando no produto logístico de alta qualidade, de avaliaram notas oito (8), nove (9) e dez (10), com maioria para nove (9) com 46,7\% e não deixando de ressaltar a porcentagem de $33,3 \%$ para a nota (10).

\section{Considerações Finais}

Esta pesquisa se propôs, como objetivo geral, analisar a Logística de distribuição e a sua influência na qualidade do produto perecível banana na empresa Sítio Barreiras, pelo qual é responsável pelo melhoramento e manutenção dos produtos e sua movimentação desde sua origem até chegar o consumidor final, aperfeiçoando os serviços satisfazendo clientes e consumidores.

No mundo globalizado em que o mercado exige praticidade e inovações constantemente, as empresas buscam acompanhar as mudanças adaptando seus serviços e produtos a esse mercado, criando técnicas e adquirindo ferramentas que ofereçam habilidades, padronização, qualidade e informações. Nas observações do objeto em estudo foi notada a preocupação da empresa em ofertar produtos e serviços diferenciados aplicando a logística de distribuição eficientemente e eficaz para alcance de suas metas.

O produto logístico por sua vez tem a finalidade de promover formação de novos clientes e maximização dos lucros por agregar valor e qualidade, obtendo uma maior fatia de mercado e consequentemente o crescimento da empresa. $\mathrm{O}$ canal de distribuição da empresa Sítio Barreiras é composto por uma gama de recursos logísticos que viabilizam as operações, tornando visível a correta empregabilidade de técnicas e procedimentos logísticos que promovem uma maior produtividade, gerando maior lucratividade com diminuição de gastos com mão de obra, tempo desperdiçados, erros, além de disponibilizar de comodidade e padronização.

A logística alinhada aos demais setores empresariais promovem este ajuste nos processos objetivando a criação de uma linha de produção e abastecimento voltada para a satisfação do mercado, um melhor nível de desempenho, visando o crescimento e a competitividade da empresa. Também observou o treinamento das pessoas com o fluxo 
contínuo de informações para alcance metas propiciando conhecimento da prática adequada e o desenvolvimento de novas atitudes e talentos.

No campo estudado a força do trabalho realizado com satisfação e a formação de lideranças em conjunto com a tecnologia e um bom gerenciamento logísticos faz com que o posicionamento da empresa perante seus clientes seja satisfatório.

Verificou-se com a aplicação do questionário aos clientes da empresa a confirmação dessa satisfação de atendimento das necessidades do cliente no tempo e no local necessário através das notas obtidas e para alavancar mais ainda estes resultados de pesquisa a empresa precisa avançar no seu setor comercial, oferecendo aos clientes além de promotores uma equipe de supervisão e vendas presentes no seu cliente, promovendo parcerias que beneficiem as relações empresa-cliente-consumidor, gerando renda, crescimento econômico e plena satisfação dos clientes e consumidores.

A empresa observada cresce a cada ano distribuindo frutas com qualidade em diversos estados, fruto deste trabalho feito com planejamento estratégico e com o olhar voltado para o futuro.

\section{Referências}

ARBACHE, F. Saba; SANTOS, A. Garnier; MONTENEGRO, C; SALES, Wladimir. Gestão logística, distribuição e trade marketing. 4ª Ed. Rio de Janeiro: FGV, 2011.

BALLOU, Ronald H. Gerenciamento da cadeia de suprimento/logística empresarial. $5^{\mathrm{a}}$ Ed. Porto Alegre: Bookman, 2010.

BALTAZAR, Bananas <http://baltazarbananas.com.br/site/index. php/curiosidades-dabanana/fases-da-banana> Acesso em : 05 nov. 2016.

BOWERSOX, Donald J; CLOSS, David J. Logística empresarial: o processo de integração da cadeia de suprimento. São Paulo: Atlas, 2010.

BOWERSOX, Donald J; CLOSS, David J; COOPER, M. Bixby. Gestão de Suprimentos e Logística. Tradução da segunda edição. Rio de Janeiro: Elsevier, 2007.

LAS CASAS, Alexandre L. Marketing: Conceitos, exercícios, casos. $8^{\text {a }}$ Ed. São Paulo: Atlas, 2009. 
CHING, Hong Yuh. Gestão de estoques na cadeia de logística integrada: supllychain. $3^{\mathrm{a}} \mathrm{Ed}$. São Paulo: Atlas, 2009.

GIL, Antônio Carlos. Como elaborar projetos de pesquisa. 5a Ed. São Paulo: Érica, 2013.

GONÇALVES, Paulo Sergio. Administração de materiais. $3^{\text {a }}$ ed. Rio de Janeiro: Elsevier, 2010 .

GUERRIERO, I. C. Z. Aspectos éticos das pesquisas qualitativas em saúde. 2006. 190 f. Tese (Doutorado em serviços de saúde pública) - Universidade de São Paulo, SP, 2006. Disponível em:<http://www.anpepp.org.br/old/arquivos/etica/GUERRIERO-tese.pdf>. Acesso em: 19 maio. 2016.

KAUARK, Fabiana da Silva; MANHÃES, Fernanda Castro; MEDEIROS, Carlos Henrique. Metodologia da pesquisa: Um guia prático. Itabuna - BA: Via Litterarum, 2010.

MARCONI, Marina de Andrade; LAKATOS, Eva Maria. Metodologia científica. $5^{\text {a }}$ Ed. São Paulo: Atlas, 2011.

LUDWIG, Antônio Carlos Will. Fundamentos e práticas de metodologia científica. $2^{\mathrm{a}} \mathrm{Ed}$. Petrópolis - RJ: Editora Vozes, 2012.

MINISTÉRIO DA SAÚDE. Resolução CNS 466/12. Dispõe sobre as "normas e regulamentos da pesquisa envolvendo seres humanos". Diário Oficial da União, Brasília, DF, 11 e 12 dez. 2012, 240ª reunião ordinária. Disponível em:

<<http://conselho.saude.gov.br/ultimas_noticias/2013/06_jun_14_publicada_resolucao.html> $>$ Acesso em: 10 maio. 2016.

NOVAES, Antônio Galvão. Logística e gerenciamento da cadeia de distribuição. Google acadêmico. $4^{\text {a }}$ Ed. Revista, atualizada e ampliada, 2015.

NOVAES, Antônio Galvão. Logística e gerenciamento da cadeia de distribuição. $2^{\mathrm{a}}$ Ed. Rio de Janeiro: Elsevier, 2004.

OLIVEIRA, Maria Marly de. Como fazer pesquisa qualitativa. $3^{\text {a }}$ Ed. Petrópolis - RJ: Editora Vozes, 2010.

POZO, Hamilton. Administração de recursos materiais e patrimoniais: Uma abordagem

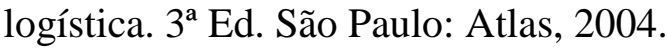

RAZZOLINI, Edelvino Filho. Logística: Evolução da Administração - Desempenho e flexibilidade. Curitiba. Juruá, 2006.

SANTANA, R. D. F. A Logística como ferramenta de competitividade na distribuição de produtos acabados: um estudo de caso na zona 146 da empresa Perdigão Agroindustrial S/A, 2006-2. Faculdade Sete de Setembro - FASETE. Trabalho de conclusão de curso (Administração de Empresa). Disponível em: 
<http://201.59.77.242/biblioteca/pdf_monografias/administracao/2006/2756.pdf> Acesso em: 01 maio. 2016.

\section{Como citar este artigo (Formato ABNT):}

NUNES, Maria das Graças C.; OLIVEIRA, Alyne Leite de; VIANA, Hudson Josino; LIMA, Antonio Raniel Silva; ALENCAR, Maria Patrícia de. Análise dos Serviços Logísticos de Distribuição de Bananas: Um Estudo de Caso na Empresa Sítio Barreiras. Id on Line Rev.Mult. Psic., 2018, vol.12, n.41, p.266-293. ISSN: 1981-1179.

Recebido: $14 / 06 / 2018$

Aceito 25/06/2018 